\title{
Character Traits of Jordanian Universities International Students Influenced by Economic - political Status
}

\author{
Amani G. Jarrar ${ }^{1} \&$ Adnan M. Odeh ${ }^{2}$ \\ ${ }^{1}$ Department of Development Studies, Faculty of Arts, Philadelphia University \\ ${ }^{2}$ Psychological Counseling Department, Philadelphia University \\ Correspondence: Dr. Amani G. Jarrar. Tel: 96-27-9552-2401. E-mail: aj8infinity@gmail.com
}

Received: October 4, $2017 \quad$ Accepted: December 9, $2017 \quad$ Online Published: January 29, 2018

doi:10.5539/ass.v14n2p105 URL: https://doi.org/10.5539/ass.v14n2p105

\begin{abstract}
The study aimed to reveal the personality traits of international students in Jordanian universities as affected by both the economic and political factors. The study sample consisted of (410) foreign students in Jordanian universities, representing males (208) and females (202). The results of the study showed that the personal characteristics of international students are mainly affected by both economic and political status of their original countries. The study showed that the most affecting factor is the economic rather than the political. The students traits were also divided in four categories or levels: The (Social) level was highest, the (emotional level) was the second in rank. The (cognitive level) ranked in the third level. And finally ranked the (cultural level). There were also differences between the average grade of individuals on the scale of personality traits and in each of its areas according to the level of education variable. The results of the study showed that there are statistically significant differences in personality characteristics according to the level of education variable in the field of knowledge and were in favor of the master while there were differences of statistical significance attributed to gender variable in favor of females.
\end{abstract}

Keywords: Character traits, international students, economic status, political status, Jordan

\section{Introduction}

The study of human personality is one of the most important topics that lead to understanding human behavior and knowledge of its motives, and its consideration of the personality of the individual, and these characteristics vary from one person to another which lead to difference in the personalities of individuals as affected by different aspects (Sarhan, 2000).

The term (personality) is derived from the Latin word (person) which means (mask), which resembles the mask that is put on the face if the individual when acting, which implies that we can choose what to hide and what to show in one's personality. And this means that some characters remain hidden (Abdel Rahman, 1998).

The concept of personality in psychology is a scientific term used specifically to present and clarify the reality of the individual. Since the beginning of the twentieth century, personal psychology has been developed through the use of special tools and methods of psychology. Psychometric and psychological tests have provided the necessary materials to study and uncover the different aspects of the personality of the individual (Abbas, 1990).

Personality is the basis of the study of psychology, so that individuals differ in terms of the composition of each, and that there are no two individuals as similar, but everyone has a unique character that distinguishes him from others (Cervone \& Pervin, 2015).

The personality occupies a prominent importance in psychological and educational studies because it determines the way people live and how they adapt to what surrounds them. Personality is the integrated interaction of the physical, mental, emotional and social characteristics that characterize a person and make him/her a unique pattern in his/her behavior and components (Abdel Rahman, 1998).

Gilford defines personality as characteristics of the individual (Sarhan, 2000). While Isaac defines personality as the relatively constant and permanent organization of an individual's creation, typography, temper, mind, and body structure, which uniquely identify one's environment as distinct from others (Khalifa, 1998).

Character traits are formed in the early stages of an individual's life and are influenced by environmental, genetic 
and social factors, and by the individual's habits and values from the surrounding environment (Ajami, 2005).

The personal characteristics of the individual constitute the construction of individual qualities and behavior and the manner of adaptation to the environment and its style in dealing with others and its ability to cope with the latest developments in life and the nature of one's abilities, motivation, emotional reactions and the nature of experiences, trends and behavior (Jurists, 2014).

When we look at a person in terms of personal components, being born as a biological unit that interacts with a larger unit, namely the unity of the physical, social and cultural environment. This interaction continues as long as the human being is alive. The personality is formed and grows, its features and fingerprints are determined and it becomes a dynamic organization within the individual which has its physical, inherited and acquired social and cultural rights that distinguish each person from another.

Physical components: The general shape of the individual and his/her physical health, performance and various body systems.

Mental components: They are the functions of the higher mind, such as general intelligence and special ability, such as numerical, linguistic, mechanical and technical abilities, as well as psychological processes such as attention, remembering and perception.

Social components: The ability of the individual to form relationships with many individuals or to form relationships with groups.

The cultural components: It is what the individual acquires and what is recognized by the cultures of the local and external environment.

Emotional components: All related to the joy and pleasure and introversion, anger and depression and other emotions and tendencies and values and trends of the activity of emotional control or tendency to submission.

All these traits and components affect in one way or another the composition of the character and its different dimensions. (Abboud, 2010).

\subsection{Problem statement and questions of the study}

The subject of personality and its characteristics occupies a great and serious interest in man in our time and is influenced by what is going on around in this world. Because Jordanian universities have paid great attention to students from all over the world, special offices have been established for them to reach out to the Jordanian society, solve and follow up their problems, coordinate their activities, introduce them to Jordan and pursue their academic, social and health conditions during their studies in cooperation with consultants and cultural attachés. In addition to organizing cultural, artistic, sport and social activities, exhibitions, cultural trips, and folklore festivals that contribute to fine-tuning their personalities and preparing them for sound entry into life.

For this purpose, this study came to identify some of the characteristics of the Jordanian students at the Jordanian universities in the bachelor, master and doctorate levels by answering the following questions:

1. What are the personality traits of Jordanian students in Jordanian universities (emotional, social, cognitive, cultural)?

2. Are there statistically significant differences at the level of $(\alpha=0.05)$ in personal characteristics due to the variable (gender, level of study)?

\subsection{Importance of the study}

The importance of this study stems from two aspects: theoretical importance and practical importance.

The theoretical importance: The importance of this study in theory is highlighted in that it explains the personality traits of the international students in the light of some variables: gender, educational level, and thus will provide more information in the light of what it has reached, and in several areas especially psychology and psychological counseling. Thus contributing to the guidance process of those involved in this area.

Practical importance: The present study provides a theoretical framework from which other studies are interested in this field of research. The study also tried to provide tools for researchers to measure the personality traits of foreign students with good characteristics in terms of honesty and stability. The importance of this study also stems from the findings and recommendations that may be provided to the students of Jordanian universities in order to develop preventive, developmental and remedial guidance programs.

\subsection{Previous studies}

Al-Zyud (2013) conducted a study aimed at identifying the extent of adaptation and compatibility of students 
studying in Jordanian universities in four areas: Academic, psychological, social and economic. To achieve this goal, a questionnaire was developed, (350) students were taken as a sample. The study found that there were no statistically significant differences in the adaptation and compatibility of expatriates due to the variable of the academic level. The highest level of quality was found in the economic sphere, followed by social and psychological fields and the lowest level of adjustment was in the academic field.

Mustafa and Sherifin (2013) also conducted a study aimed at revealing the relationship between the sense of psychological unity and psychological security among a sample of foreign students studying at Yarmouk University. The sample of the study consisted of (158) students who were chosen by the Intended method of Yarmouk University students enrolled in the second semester of the academic year (2015-2016). To achieve the objective of the study, two measures were constructed to measure the sense of loneliness and psychological security. The results of the study indicated that the level of psychological unity among the foreign students was average, and that all correlation coefficients between the two measures were statistically significant at the level of $(\alpha=0.05)$ except after the subjective feelings according to the measure of psychological security, its dimensions and negative direction. The results also showed statistically significant differences in the level of psychological unity as a whole, and in the areas of family relations and subjective feelings attributed to gender and to females. There were also differences in the level of psychological unit due to the level of achievement. And for those with excellent achievement and low achievers (acceptable). In addition to a difference in the level of psychological sense of security on the scale as a whole and in all areas attributed to gender and for the benefit of males.

Tatech (2007) conducted a study entitled "Nostalgia and its relationship to the motivation of academic achievement among Arab students at the University of Baghdad" aimed at exploring the nostalgia of Arab students to study at the Iraqi University and examining its relationship with the academic achievement. The researcher designed for this purpose the measure of country nostalgia, which consists of (41) paragraphs on a sample of (238)new Arab students, which are 161 male students and 77 female students. The results of the study showed that the new Arab students suffer from nostalgia for homeland, and it is spread among $(90 \%)$ in the research sample, there was no gender differences in terms of feeling nostalgic. As for the motivation for academic achievement, the new Arab students were also known for their high level of achievement, representing $95 \%$ in the research sample. There were no differences between males and females.

In a descriptive study of the level of some of the personal characteristics of the students of Amman Private University and its relation to some variables, Sualha and Al-Abushi (2011) aimed at identifying the degree of some personal characteristics (balance, rationality, responsibility, assertiveness, decision making, social ability, creativity, according to Amman University, trying to find out if there are statistically significant differences in these personal characteristics according to some variables. The study sample consisted of (537) students from scientific and literary faculties. The results indicated that the level of the measured personality traits was moderate. The results also indicated that there were no statistically significant differences between the sample of the study in terms of the level of personality traits due to the variable of the number of credit hours adopted by the students on each of the seven attributes and on the total scale, while the differences were statistically significant personality traits depending on gender variables, type of faculty, and cumulative rate of student.

In a study conducted by Al-Saghir (2011) on the social adjustment of students to King Saud University, the study found that there is a difference in the level of adaptation among foreign students at King Saud University, whether social, cultural, academic, demographic or economic adjustment. The lack of knowledge of the language, knowledge of the customs and traditions of Saudi society, as well as the lack of adaptation to the faculty members, and the study found that the degree of adaptation varies according to the marital status of the immigrant student as the unmarried student adapts more than the married student.

Farfel et al. (2004) conducted a study aimed at identifying the extent to which personality traits contributed to the efficiency of the team, with a sample of 188 students enrolled in Nebraska University programs, Engineering Program. The results of the study showed that there is some correlation between the training of individuals in the form of personality and improvement in the skill of communication and the degree of efficiency and independence of the team, and the results showed that there was no statistical correlation between the personal pattern and the measure of efficiency in work.

\subsection{Study determinants}

- The results of the present study are determined by the study tools and their psychometric characteristics.

- The sample of the study was limited to the foreign students in the Jordanian universities, and therefore their results can be distributed to samples that have the same characteristics of the study sample. 


\subsection{Terminology}

Personality traits known as a complete set of reactions and responses that are linked by a type of unity, while defined by Gordon as a general central nervous system characterized by the individual (Tafesh, 2006).

The researcher defines the procedure in the degree to which the respondent obtains the personality traits used in this study.

The foreign student is an incoming university student studying at one of the Jordanian universities chosen for this study.

\subsection{Seven Character Traits in Education}

Respect: To show respect for something means to treat it as valuable and worthy. A person should exhibit respect for him/herself, other people, property, and the environment. Those who show respect:

- Care about others' feelings

- Are courteous and polite

- Honor roles of authority.

Responsibility: To be responsible means to be accountable for one's own actions and to know and follow laws, rules, and conduct codes. Those who are responsible:

- $\quad$ Think before acting

- Accept the consequences of their actions

- $\quad$ Keep Promises

- $\quad$ Are dependable.

Kindness: To be kind means to treat other people as you want to be treated. Those who are kind:

- Show compassion

- Show empathy

- Are considerate

- Are unselfish

- $\quad$ Are friendly Are helpful.

Perseverance: To persevere means to complete a task even when it becomes boring, difficult, or discouraging. Those who show perseverance:

- Work hard toward goals

- Overcome obstacles

- $\quad$ Do not give up easily

- Are resourceful in reaching a goal.

Self-Discipline: To be self-disciplined means to control one's behaviors and emotions and, when necessary, to postpone immediate needs/desires for long-term benefits. Those who are self-disciplined:

- Show self-control

- Do things in moderation

- Show patience

- Develop effective habits

Honesty: To be honest means to be truthful, trustworthy, and behave with integrity. Those who are honest:

- Do not mislead others

- $\quad$ Are forthright

Fairness: To be fair means to promote equal opportunity for everyone and to apply agreed upon rules equally to everyone. A fair person: Is impartial Is without prejudice Is just Collier County Public Schools. Character Education

The ancient Greek philosopher Theophrastus was an early student of human personality. His character sketches, which depict people in their public and private dealings, underscore the essential insight of modern personality 
research: behaviors across what might at first seem like unrelated domains are correlated, and behavioral patterns can be explained by reference to underlying personality types. In recent years, personality psychologists have refined our understanding of personality and have reached a working consensus that personality traits can be comprehensively conceptualized and reliably measured in terms of five traits (the Big Five): Agreeableness, Openness (to Experience), Emotional Stability (sometimes referred to by its inverse, Neuroticism), Conscientiousness, and Extraversion. Individual personality is shaped by experience-family dynamics, cultural forces, work experiences, and educational experiences. However, a great deal of evidence indicates that substantial variation in foundational personality dispositions such as the Big Five are stable from very early in life. Research finds that Big Five traits can explain substantial amounts of variation in a variety of opinions, behaviors, and outcomes.

\section{Method and procedures}

\subsection{Study sample}

The University of Philadelphia, University of Jordan, Hashemite University and Petra University, have been chosen as an accessible society and in light of practical reasons such as providing study personnel and the means to facilitate the study procedures and their implementation. The study tool was distributed to the study sample members. After the initial screening of the responses of the foreign students on the sample of the study tool, it was found that the number of questionnaires returned and filled was (430), out of which (20) were excluded because they were not complete or because of the credibility of the study results. Thus, the total number of accepted questionnaires reached (410) as shown in table 1.

Table 1 . The distribution of the study sample by gender and level of education

\begin{tabular}{|c|c|c|c|}
\hline Gender & Level of education & Frequency & Percentage \\
\hline & BA & 96 & $23.4 \%$ \\
\hline \multirow[t]{3}{*}{ Male } & M.A & 66 & $16.0 \%$ \\
\hline & Ph.D & 40 & $10.0 \%$ \\
\hline & BA & 125 & $30.4 \%$ \\
\hline \multirow{3}{*}{ Female } & M.A & 71 & $17.6 \%$ \\
\hline & Ph.D & 12 & $3.0 \%$ \\
\hline & & 410 & $100 \%$ \\
\hline
\end{tabular}

2.2 Study tool

\subsubsection{Personal Attributes Scale}

In order to identify the level of personal characteristics of the international students, the researcher has developed a multi-disciplinary personality scale, based on the theoretical literature and previous studies, consisting of (27) paragraphs divided into fields (emotional, social, cognitive, cultural).

\subsubsection{Signs of validity and reliability of the scale}

Benchmark indicators were found using the following methods:

- Content validity: For the purposes of the current study and to verify the validity of the virtual scale, the scale was presented in its initial form, consisting of (30) paragraphs, on (10) arbitrators with expertise in the field of psychological counseling and psychology in Jordanian universities. They were asked to judge the accuracy and validity of the language and the clarity of the paragraphs and its relevance to the ultimate objective of the measure. A consensus of nine arbitrators has been adopted to accept the paragraphs and retain them as they are by agreement $(90 \%)$, and amend them if two arbitrators propose amendment. No paragraph was deleted, and some paragraphs were amended on the basis of the opinion of the arbitrators.

- Study structure validity: The correlation between the grade on each paragraph was calculated by the total score of the scale and the field to which it was developed. Table (2) explains this.

It is clear from Table (2) that the values of the correlation coefficients between the paragraphs of the scale with the total score ranged between (44.0 - 0.89) and the correlation coefficients of the paragraphs in their range $(0.47$ - 0.88), all of which exceeded (0.25) (Odeh, 2010). The level $(0.5 \alpha \alpha)$ is a good indicator to judge the validity of the tool. The researcher also calculated the correlation coefficients between the domains and the total score of the scale. And table (3) shows that. 
Table 2. Coefficient factors as linked to each paragraph and measure of personality traits distributed to scale and field values

\begin{tabular}{|c|c|c|c|c|c|c|c|c|}
\hline $\begin{array}{c}\text { Paragraph } \\
\text { number }\end{array}$ & $\begin{array}{l}\text { Coefficient } \\
\text { factor }\end{array}$ & $\begin{array}{l}\text { Field } \\
\text { factor }\end{array}$ & $\begin{array}{c}\text { Paragraph } \\
\text { number }\end{array}$ & $\begin{array}{l}\text { Coefficient } \\
\text { factor }\end{array}$ & $\begin{array}{l}\text { Field } \\
\text { factor }\end{array}$ & $\begin{array}{c}\text { Paragraph } \\
\text { number }\end{array}$ & $\begin{array}{l}\text { Coefficient } \\
\text { factor }\end{array}$ & $\begin{array}{l}\text { Field } \\
\text { factor }\end{array}$ \\
\hline 1 & $* * 0.65$ & $* * 0.86$ & 11 & $* * 0.66$ & $* 0.64$ & 21 & $* 0.55$ & $* * 0.77$ \\
\hline 2 & $* * 0.67$ & $* * 0.76$ & 12 & $* * 0.75$ & $* * 0.67$ & 22 & $* * 0.76$ & $* * 0.81$ \\
\hline 3 & $* * 0.86$ & $* * 0.74$ & 13 & $* * 0.70$ & $* * 0.70$ & 23 & $* * 0.64$ & $* 0.60$ \\
\hline 4 & $* * 0.79$ & $* * 0.80$ & 14 & $* * 0.66$ & $* 0.63$ & 24 & $* * 0.77$ & $* 0.88$ \\
\hline 5 & $* * 0.65$ & $* * 0.82$ & 15 & $* 0.44$ & $* * 0.76$ & 25 & $* * 0.69$ & $* 0.56$ \\
\hline 6 & $* * 0.66$ & $* * 0.73$ & 16 & $* * 0.65$ & $* * 0.71$ & 26 & $* * 0.67$ & $* 0.49$ \\
\hline 7 & $* * 0.75$ & $* 0.66$ & 17 & $* * 0.64$ & $* 0.60$ & 27 & $* * 0.76$ & $* 0.59$ \\
\hline 8 & $* * 0.70$ & $* 0.69$ & 18 & $* * 0.70$ & $* 0.68$ & 28 & $* * 0.70$ & $* 0.62$ \\
\hline 9 & $* * 0.66$ & $* 0.59$ & 19 & $* * 0.65$ & $* 0.66$ & 29 & $* * 0.65$ & $* 0.58$ \\
\hline 10 & $* 0.44$ & $* 0.63$ & 20 & $* * 0.89$ & $* 0.47$ & 30 & $* 0.60$ & $* 0.63$ \\
\hline
\end{tabular}

Table 3 . The correlation coefficients as related to personality traits domains and scales

\begin{tabular}{ccccc}
\hline Feild & Emotional & Social & Cognitive & Total \\
\hline Emotional domain & - & - & - & $* * 0.79$ \\
Social domain & $* 0.65$ & - & - & $* 0.56$ \\
Cognitive domain & - & $* 0.58$ & - & $* 0.69$ \\
Cultural domain & $* 0.60$ & $* * 0.80$ & $* * 0.72$ & $* * 0.84$ \\
\hline
\end{tabular}

** Statistical significance at level $(\alpha=0.01) \quad *$ Statistical significance at $(\alpha=0.05)$

It is clear from Table (3) that all correlation coefficient values between the fields are statistically significant, ranging between $0.51-0.80$, while correlation between the fields and the scale ranged between $0.56-0.84$. Thus, the measure in its final form shall be of (30) paragraphs.

\subsubsection{Stability of personality traits scale}

The researcher was able to derive indicators of stability of the scale using the method of internal consistency and testing different times, and the scale was applied to the survey sample from the study community and from outside the sample. The scale was applied to the same sample at a time interval of two weeks. The internal consistency values of the scale as a whole and for each field were calculated using the $\alpha$-Cronbach coefficient, and the middle term splitting, and Table (4) shows the stability results.

Table 4. The stability coefficients of the scale by its sub - dimensions and its total significance using the Alpha Kronbach equation and the middle term splitting reliability method

\begin{tabular}{ccccc}
\hline Field & Number of paragraphs & Repeating the test & Alpha Kronbach & Middle term splitting reliability \\
\hline Emotional & 12 & 0.88 & 0.81 & 0.79 \\
Social & 5 & 0.71 & 0.89 & 0.82 \\
Cognitive & 10 & 0.66 & 0.79 & 0.88 \\
Cultural & 10 & 0.80 & 0.87 & 0.66 \\
Total & 37 & 0.74 & 0.75 & 0.82 \\
\hline
\end{tabular}

The results of Table (4) indicate that stability coefficients using $\alpha$-Cronbach equation ranged from 0.75 to 0.89 and the total score $(0.75)$, all of which are statistically significant at 0.05 . The values of the stability coefficient ranged from 0.76 to 0.88 and reached the total score of 0.82 . All of these were statistically significant at $0.05 \alpha$. The re-test correlation coefficients ranged from (066 to 0.88 ) to 0.74 ). This indicates the accuracy of the scale.

\subsubsection{Correction of personality traits scale}

The measure consists of (30) paragraphs, divided into (4) areas, the emotional field (8) paragraphs, the social area (8) paragraphs, the cognitive field (7) paragraphs, the cultural field (8) paragraphs, with a scale of (always, often, rarely, never), depending on the content of the paragraph on the subject. The answer scale has been converted to degrees as follows: always $=5$, often $=4$, sometimes $=3$, rarely $=2$, Never $=1$, so the total score that can be obtained on the scale ranges from (30-150) degrees. The grade (111.08) and above was considered 
the degree of the cut point and the measure of the level of personality traits, which represents (33.4\%) of the total score of the scale.

In order to classify the level of personality traits by their total significance to three levels (high, medium, low), the equation was adopted:

$\frac{\text { The highest level of measurement }- \text { the lowest level of measurement }}{3}=\frac{5-1}{3}=1.33$

Levels of response to the scale shall be as shown in Table (5) below:

Table 5. Level of scores for calculating the level of personality traits

\begin{tabular}{cc}
\hline Low level of personality traits & $1-2.33$ \\
\hline Average level of personality traits & $2.34-3.67$ \\
\hline High level of personality traits & $3.68-5$ \\
\hline
\end{tabular}

\subsection{Study Procedures}

After the preparation of the study tool, finding the validity and reliability of coefficients, and obtaining the official approvals for the study, the study tool was distributed to the sample of the study, explaining to the examinees the importance of the research and its objectives and how to answer the questionnaire, stressing that the answers will be used only for the purposes of scientific research, The treatment will be taken with total confidentiality.

\subsection{Study Approach}

The nature of the study necessitated the use of the descriptive method. This is because of its ability to contribute to providing us with the necessary information to identify the level of personality traits of the international students, and then to analyze this information and interpret it to reach the results that can contribute to achieving the objectives of the desired study.

\subsection{Statistical processing:}

To perform the statistical analysis after the measurement in the present study, the data were entered electronically, and analyzed using SPSS, as follows:

- To answer the first question, the arithmetical averages and the standard deviations of the estimates of the study group members were used for each area of the study instrument.

- To answer the second question, the multiple variance analysis (MANOVA), and the Scheffe test were used.

\section{Results}

- $\quad$ Results related to the first question: "What is the level of personality traits of foreign students in Jordanian universities?" To answer this question, the arithmetical averages, the standard deviations of the scores of the sample were calculated on the personality traits scale, and table 6 shows the results.

Table 6. The arithmetical averages and standard deviations for each of the domains of the personality attribute scale as arranged in descending order

\begin{tabular}{ccccc}
\hline Field & Arithmetic means & Standard Deviation & Percentage & Level \\
\hline Social & 3.86 & 0.75 & $\% 77.0$ & High \\
Emotional & 3.79 & 0.66 & $\% 75.8$ & High \\
Cognitive & 3.77 & 0.80 & $\% 75.5$ & High \\
Cultural & 3.76 & 0.74 & $\% 75.0$ & High \\
\hline
\end{tabular}

Table (6) shows that the most common personality traits are the social with the means (3.86), standard deviation of (0.75), percentage (77\%), high level, emotional field with means (3.79), standard deviation of (0.66) (3.77), standard deviation (0.80), percentage (75.5\%), high level, cultural domain with means of (3.76), standard deviation (0.74), a percentage of (75\%) and a high level.

- Results on the second question: Are there statistically significant differences at the level of significance $(\alpha=0.05)$ in personal characteristics due to the variable of educational level?

In order to determine the significance of the differences between the averages according to the educational level variable, the arithmetic averages and the standard deviations were calculated according to the personality scale. 
Table 7. Arithmetical means and standard deviations according to the educational level variable on the scale of personality traits

\begin{tabular}{cccc}
\hline Dimension Variable & Level of variable & Arithmetic Means & \multicolumn{2}{c}{ Standard Deviation } \\
\hline \multirow{2}{*}{ Emotional } & BA & 3.72 & .810 \\
& Master's & 3.99 & 210 \\
\multirow{2}{*}{ Social } & Ph.D & 3.75 & 0.44 \\
& BA & 3.80 & .670 \\
& Master's & 4.09 & .860 \\
Cognitive & Ph.D & 3.81 & .690 \\
& BA & 3.73 & .020 \\
& Master's & 4.03 & .480 \\
cultural & Ph.D & 3.61 & .120 \\
& BA & 3.70 & .160 \\
\hline
\end{tabular}

Table 7 shows the existence of a virtual difference between the average scores of individuals on the scale of personality traits and in each of its domains according to the variable of the educational level. To find out the significance of the differences between the averages according to the educational level variable, one-way manova.

Table 8. ONE-WAY MANOVA analysis of the age variable on the scale of personality traits

\begin{tabular}{ccccccc}
\hline $\begin{array}{c}\text { Source of } \\
\text { Variance }\end{array}$ & $\begin{array}{c}\text { Dependent } \\
\text { variables }\end{array}$ & $\begin{array}{c}\text { Sum of } \\
\text { squares }\end{array}$ & $\begin{array}{c}\text { Degrees of } \\
\text { Freedom }\end{array}$ & $\begin{array}{c}\text { Average of } \\
\text { squares }\end{array}$ & $\begin{array}{c}\text { F } \\
\text { value }\end{array}$ & $\begin{array}{c}\text { Significance } \\
\text { Level }\end{array}$ \\
\hline \multirow{3}{*}{ Educational level } & emotional & 4.922 & 2 & 2.461 & 5.752 & 0.033 \\
& social & 6.078 & 2 & 3.039 & 5.502 & 0.024 \\
& cognitive & 8.688 & 2 & 4.344 & 6.865 & 0.001 \\
& cultural & 6.134 & 2 & 3.067 & 5.707 & 0.071 \\
& emotional & 174.143 & 407 & 0.428 & & \\
Error & social & 224.802 & 407 & 0.552 & & \\
& cognitive & 257.538 & 407 & 0.633 & & \\
& cultural & 218.710 & 407 & 0.537 & & \\
& emotional & 6070.620 & 410 & & & \\
\end{tabular}

Table (8) shows that there are no statistically significant differences at the level of $(\alpha \leq 0.05)$ for the educational level variable on the scale as a whole and on the domains (emotional, social, cultural). However, there were statistically significant differences at the level of $(\alpha \leq 0.05)$ for the educational level variable on the cognitive field, where the level of significance $(0.01)$ is less than $(\alpha=0.05)$, and to know the direction of differences between the averages of the responses of individuals around the cognitive field according to the variable $F$ or any level, a Scheffe comparison test was used as shown in table (9).

Table 9. Scheffe test of the post comparisons according to the educational level variable on the cognitive field

\begin{tabular}{ccccc}
\hline Educational level & Arithmetical means & BA & Master's & Ph.D \\
\hline Scheffe & & 3.73 & 4.03 & 3.61 \\
BA & 3.73 & ----- & 0.83 & 0.29 \\
Master's & 4.03 & ----- & ----- & $* 0.005$ \\
\hline
\end{tabular}

The results of Table (9) show that there are statistically significant differences according to the field of knowledge of the educational level variable and for the master's degree, where the level of significance is (0.005).

- Results related to the third question: "Are there statistically significant differences at the level of $\alpha$ $(0.05)$ in personality traits due to the gender variable?"

To answer the question, a T- test was used for the independent samples as shown in the table below: 
Table 10. (T)Test of independent samples of gender variable on the personality traits scale

\begin{tabular}{ccccccc}
\hline \multirow{2}{*}{$\begin{array}{c}\text { Dependent } \\
\text { variables }\end{array}$} & $\begin{array}{c}\text { Arithmetic } \\
\text { means }\end{array}$ & $\begin{array}{c}\text { Standard } \\
\text { deviation }\end{array}$ & $\begin{array}{c}\text { Arithmetic } \\
\text { means }\end{array}$ & $\begin{array}{c}\text { Standard } \\
\text { deviation }\end{array}$ & $\begin{array}{c}\text { Female } \\
\text { value }\end{array}$ & $\begin{array}{c}\text { Level of } \\
\text { significance }\end{array}$ \\
\cline { 2 - 5 } Emotional aspect & 3.6772 & 0.69229 & 3.8528 & 0.63711 & -2.58 & 0.01 \\
Social aspect & 3.7310 & 0.77782 & 3.9453 & 0.72680 & -2.78 & 0.006 \\
Cognitive aspect & 3.6966 & 0.77459 & 3.8236 & 0.82185 & -1.52 & 1.28 \\
Cultural aspect & 3.6867 & 0.74446 & 3.8280 & 0.73640 & -1.85 & 0.06 \\
\hline
\end{tabular}

The results of Table (10) indicate that there are statistically significant differences in the gender variable at $(0.05$ 0.05 ) for both the emotional and social domains and for the females, while there were no differences in terms of knowledge and culture.

\section{Study Results Discussion}

First, to discuss the results related to the first question, which is: "What is the level of personality traits of students in Jordanian universities?" The results of this question showed that the most character traits significant in International students

Were the social traits, it was high in level, followed by the emotional field that came in the second place at a high level also, then the cognitive field that was in a high level, and finally the cultural field being at a high level too. This is due to the fact that social interaction in this group is one of the most important personal things through which the foreign student is able to adapt to with colleagues through the formation of a network of social relations within the exchange of ideas, and the pursuit of this group to the psychological stability through the network of friends. The study of Zyood (2013), which aimed to know the compatibility and adaptation level of international students studying in Jordanian universities, where the results of this study indicate the high level of social adjustment compared to other areas, and it was different than the study of (Al-sagheer, 2011) which aimed to know the level of social adjustment among students coming to Saudi universities, where the results indicated a low level of social adjustment in this category.

Second, to discuss the results of the second question: Are there statistically significant differences at the level of significance $(\alpha=0.05)$ in personal characteristics due to the variable of educational level?

The results showed that there were no statistically significant differences at the level of $(\alpha \leq 0.05)$ for the educational level variable on the scale as a whole and on the domains (emotional, social, cultural). But there were significant differences in the cognitive field, for the variable of educational level and for the benefit of master's students. The researcher attributed this finding to the fact that the master's students are able to obtain the necessary information to enable them to have adequate learning, and show a constant willingness to accept the knowledge of others and the surrounding society. This result is consistent with the study of Al-sagheer, 2011) aimed at detecting social and academic adjustment of students of King Saud University. The results of the current study were also agreed with the study of (Zyood, 2013).

Thirdly, to discuss the results related to the third question: Are there statistically significant differences at the level of $(\alpha=0.05)$ in personality traits due to the gender variable?

The results indicated that the characteristics of the international students differed according to gender and in favor of females. In other words, females had a higher level of personality in the emotional, social, cultural and cognitive fields than males. This result is consistent with the results of Mustafa and Sherifin (2013).

Finally, it was revealed that character traits of International students in Jordanian universities were affected by both economic and political status of their original countries, but it was clear that the political status of their countries more affected their emotional and social level, while the economic status more affected the cultural and cognitive levels.

\section{Recommendations}

Directing the Jordanian universities to prepare educational programs for the international students to cover the different aspects affecting the personality traits, particularly the educational, social and psychological aspects.

Urging researchers to make more studies on foreign students studying their various social, psychological, economic and educational issues.

Conducting more researches on the effect of both economic and political status of students' countries. 


\section{References}

Aboud, H. (2010). Some personal traits in practices of athletes, Center for Childhood and Motherhood Research, University of Diyala. Diyala, Iraq.

Al-Ajmi, S. (2005). Relationship of some personality traits to the deviation of events in the city of Riyadh. Master's Thesis, Neve Arab University for Foreign Sciences, Riyadh.

Al-Ashqar, A. (2003). Psychological Stress of Foreign Students and Their Counseling Needs. University Dissertation, Sana'a University, Yemen.

Alfuqaha, E. (2014). Introduction to Psychology. Amman: Dar Al Baraka.

Al-Sagheer, \& Mohammed. (2001). The Social Adaptation of Expatriates Students: An Analytical Study Applied to Students at King Saud University, Riyadh.

Cervone, D., \& Pervin, L. A. (2015). Personality, binder ready version: theory and research. John Wiley \& Sons.

Kariuki, P., \& Williams, L. (2006). The Relationship between Character Traits and Academic Performance of AFJROTC High School Students. Mid- South Educational Research Association.

Khalifa, A. (1998). Some characteristics of the fateful character and its dimensions. Journal of Psychology, (48). Cairo: Egyptian General Book Organization.

Mustafa, \& Sherifin. (2013). The sense of psychological unity and psychological security in relationship to sample of international students at Yarmouk University. Journal of Educational Sciences, 9(2).

Nguyen, N. T., Allen, L. C., \& Fraccastoro. K. (2005). Personality Predicts Academic Performance: Exploring the Moderating Role of Gender (pp. 105-116). Association for Education Management. https://doi.org/10.1080/13600800500046313

Sarhan, et al. (2000). The Relationship between Personal traits and Academic Adaptation among Al-Bayt University Students. Master's Thesis, Department of Educational Sciences, Al-Bayt University, Jordan.

Sawalha, et al. (2011). Descriptive study of the level of some of the personal characteristics of the students of Amman Private University and its relation to some variables. Journal of Psychological Sciences, (19).

Tatech. (2007), The nostalgia for the homeland and its relationship to the motivation of academic achievement among Arab students at the University of Baghdad. Journal of Humanities, B(28), 155-173.

Varvel, T., Adams, S., Pridie S., \& Ulloa, B. (2004). Team Effectiveness and Individual Myers-Briggs Personality Dimensions. Journal of Management in Engineering, 141-147. https://doi.org/10.1061/(ASCE)0742-597X(2004)20:4(141)

Zyood, I. (2013). The Extent of Adaptation of Foreign Students in Jordanian Universities to the Living and learning Conditions. Jordanian Journal of Social Sciences, 6(3).

\section{Copyrights}

Copyright for this article is retained by the author(s), with first publication rights granted to the journal.

This is an open-access article distributed under the terms and conditions of the Creative Commons Attribution license (http://creativecommons.org/licenses/by/4.0/). 